Journal of Islamic Medicine

Volume 2 (4) (2018), Pages 14-25

\title{
Pengetahuan Perawat Ruang Rawat Inap Tentang Penerapan Sasaran Keselamatan Pasien
}

\author{
Riskiyah $^{1}$ \\ ${ }^{1}$ Program Studi Pendidikan Dokter, Fakultas Kedokteran dan Ilmu Kesehatan Universitas \\ Islam Negeri Maulana Malik Ibrahim Malang \\ Email : riskiyahdr@gmail.com
}

\begin{abstract}
ABSTRAK
Keselamatan pasien (patient safety) merupakan bagian penting dari mutu pelayanan kesehatan di rumah sakit. Perawat yang memiliki pengetahuan tentang keselamatan pasien dapat memperkecil risiko terjadinya hal yang membahayakan maupun merugikan pasien. RS $\mathrm{X}$ merupakan rumah sakit Ibu dan Anak dimana disana masih ada insiden keselamatan pasien yang terjadi meskipun sosialisasi dan pelatihan tentang patient safety sudah dilakukan. Tujuan penelitian ini untuk mengeksplorasi secara mendalam pengetahuan perawat tentang penerapan sasaran keselatan pasien. Metode yang dipakai adalah kualitatif fenomenologi. Wawancara secara mendalam kepada 8 informan. Hasil penelitian didapatkan enam tema yaitu pengetahuan perawat tentang penerapan SKP berupa ketepatan identifikasi pasien; peningkatan komunikasi yang efektif; peningkatan keamanan obat yang perlu diwaspadai; kepastian tepat lokasi, tepat prosedur dan tepat pasien operasi; pengurangan risiko infeksi; pengurangan risiko pasien jatuh. Kesimpulannya sebagian besar perawat rawat inap RS X mempunyai pengetahuan dan pemahaman yang baik tentang penerapan sasaran keselamatan pasien.
\end{abstract}

Kata kunci : patient safety, sasaran keselamatan pasien, pengetahuan

\begin{abstract}
Patient safety (patient safety) is an important part of the quality of health services at the hospital. Nurses who have knowledge of patient safety can minimize the risk of things that harm the patient. X Hospital is a Mother and Child hospital where there are still incidents of patient safety that occur even though socialization and training on patient safety has been carried out. The purpose of this study was to explore in depth the nurses' knowledge about the application of targets throughout patients. The method used is qualitative phenomenology. Indepth interviews with 8 informants. The results showed six themes, namely nurses' knowledge about the implementation of patient safety goal in the form of patient identification accuracy; improved effective communication; improved drug safety that needs to be watched out; certainty of exact location, proper procedure and right patient surgery; reducing the risk of infection; reduced risk of patients falling. In conclusion, most of the inpatient nurses at X Hospital have good knowledge and understanding of the implementation of patient safety goals.
\end{abstract}

Keywords: patient safety, patient safety goals, knowledge 


\section{Latar Belakang}

Keselamatan pasien (patient safety) merupakan bagian penting dari mutu pelayanan kesehatan di rumah sakit dan menjadi pusat perhatian di seluruh dunia. Keselamatan pasien (patient safety) adalah suatu prosedur yang dilakukan oleh rumah sakit untuk memberikan pelayanan yang aman kepada pasien yang dipengaruhi oleh pengetahuan dan penerapan dari perawat sebagai pelaksana yang mengutamakan kepentingan maupun keselamatan pasien (1). Semakin tinggi tingkat pengetahuan perawat tentang keselamatan pasien maka praktek keselamatan pasien dalam asuhan keperawatan semakin baik adalah benar (2). Ini berarti perawat yang mempunyai pengetahuan tentang keselamatan pasien dapat memperkecil risiko terjadinya insiden keselamatan pasien atau hal yang membahayakan maupun merugikan pasien.

Adanya suatu kegagalan untuk menyelamatkan pasien dari bahaya berhubungan juga dengan perawatan personil dari kelompok terbesar tenaga kesehatan yaitu perawat (3). Perawat merupakan tenaga kesehatan yang jumlahnya cukup banyak yaitu sebesar 50 sampai $60 \%$ dari jumlah tenaga kesehatan lain yang ada di rumah sakit (4). Saat melakukan pekerjaannya, perawat merupakan petugas yang paling sering berhubungan dengan pasien. Insiden keselamatan pasien dapat terjadi karena ada perawat yang bekerja selama 24 jam serta banyaknya pekerjaan yang harus mereka kerjakan $(2,4)$.

Data terkait kejadian tidak diinginkan maupun kejadian hampir cidera hanya sedikit tetapi banyak laporan dari masyarakat terkait malpraktek. Perawat yang melakukan kesalahan kepada pasien ada sekitar 28,3\%. Agar tidak terjadi kesalahan pada pasien maka perawat harus mengerti tugas serta perannya sehingga dapat menerapkan dengan maksimal patient safety ini (5).

RS X adalah rumah sakit swasta khusus ibu dan anak yang sudah berdiri sejak tahun 2005 dan terletak di kota Malang. RS X merupakan rumah sakit swasta tipe C yang telah terakreditasi Komisi Akreditasi Rumah Sakit (KARS). Berdasarkan wawancara dengan Direktur RS X meskipun sosialisasi dan pelatihan tentang patient safety sudah dilakukan tetapi masih ada insiden keselamatan pasien yang terjadi disana diantaranya indentifikasi pasien masih belum berjalan dengan baik karena masih ada pasien rawat inap ada yang tidak dipasang gelang identitas sampai dengan pasien pulang, masih ada kesalahan dalam pemberian obat kepada pasien oleh petugas, pemberian dobel obat kepada pasien yang isinya sama dan adanya pasien jatuh. Dari latar belakang diatas maka perlu dilakukan suatu penelitian untuk mengeksplorasi secara mendalam pengetahuan perawat tentang penerapan sasaran keselamatan pasien. 


\section{Metode}

Penelitian ini memakai metode penelitian kualitatif fenomenologi dengan cara mewawancarai secara mendalam kedelapan informan yang ada di tiap kelas RS X kecuali ruang VIP. Penelitian ini dilakukan pada bulan Juli-September 2016. Informan yang dipilih memenuhi kriteria yaitu perawat yang bekerja di Instalasi Rawat Inap RS X kelas III, II, I dan VIP; bekerja lebih dari satu tahun; mewakili pria maupun wanita; tingkat pendidikan D3, S1 (sarjana); berusia diatas 21 tahun.

\section{Hasil}

Salah satu bagian dari patient safety adalah sasaran keselamatan pasien atau disingkat dengan SKP. SKP ini terdiri dari enam macam untuk menjamin keselamatan pasien dari kesalahan tindakan petugas ketika pasien menjalani pengobatan di rumah sakit. Pada penelitian ini terdapat enam tema pengetahuan perawatan tentang penerapan patient safety antara lain:

\section{a. Pengetahuan Perawat tentang Penerapan SKP Berupa Ketepatan Identifikasi Pasien}

Pengetahuan perawat rawat inap untuk mengidentifikasi pasien sebelum melakukan berbagai tindakan sangat penting untuk diketahui agar perawat tepat pasien dan tidak salah orang. Berikut ini beberapa kutipan pernyataan informan tentang pengetahuan mereka akan penerapan standar keselamatan pasien berupa ketepatan identifikasi pasien:

'Kita mau masukkan obat oral maupun injeksi kita minta untuk semua pasien menyebutkan nama sama tanggal lahirnya. Jadi kita kroscek juga sama gelangnya'. (P103060717.02)

'Sebelum memberikan terapi kita menanyakan pasien baik nama sama tanggal lahir kemudian konfirmasi dengan melihat gelangnya. Gelangnya kan ada identitas sama tanggal lahir pasien itu. Jadi selain kita tanya tetap kita lihat dari identitas gelangnya'. (A102060717.02)

Semua informan yang merupakan perawat di ruang rawat inap RS X dalam melakukan ketepatan identifikasi mereka selalu menanyakan nama dan tanggal lahir pasien sebelum memberikan terapi atau tindakan apapun. Para informan juga mengecek gelang identitas yang dipasang pada tangan pasien apakah nama dan tanggal lahirnya cocok dengan yang disebutkan oleh pasien. Untuk pemberian obat biasanya petugas juga mencocokkan nama yang ada diobat dengan nama yang disebutkan oleh pasien serta pada gelangnya.

\section{b. Pengetahuan Perawat tentang Penerapan SKP berupa Peningkatan Komunikasi yang Efektif}


Pengetahuan perawat tentang penerapan komunikasi yang efektif kepada dokter, pasien maupun sesama perawat sangat penting. Adanya komunikasi efektif ini mencegah agar tidak terjadi kesalahan pengobatan kepada pasien. Berikut ini beberapa kutipan pernyataan informan tentang pengetahuan mereka akan penerapan SKP berupa peningkatan komunikasi yang efektif:

'Kita mengulang apa yang di yang terapinya yang dikatakan. Kalo kurang jelas ya kita eja ABCD nya. Intinya kalo kurang jelas tapi walaupun kita tetap ngulang apa yang sudah kita trima pertelphone ini kita ulang lagi. Jadi terapi apa kita ulang lagi. Kita tulis di S-Barnya. Pas dokter visite kita minta notasinya'”. (A102060717.05)

'Misalkan kita telephone, kita lapor ke dokter. Kita menggunakan metode S-Bar. SBAR itu jadi kita itu dokumentasinya kalo komunikasinya kita telephone. Kita konfirmasi ulang. Kita baca kembali sampek dokternya bilang iya betul. Jadi ada timbal baliknya'. (P103060717.04)

Sebagian besar menyatakan bahwa komunikasi efektif dalam sasaran keselamatan pasien ini adalah jika berkonsultasi melalui telephone maka perawat menggunakan metode S-BAR. $\mathrm{S}$ adalah singkatan dari situation yang berarti apa yang akan dilaporkan kepada dokter penanggung jawab. B adalah singkatan dari background yang artinya melaporkan keadaan pasien saat itu. A adalah singkatan dari assesment yang artinya diagnosa pasien. Terakhir adalah $\mathrm{R}$ yang merupakan kepanjangan dari recommendation atau rekomendasi dari dokter.

Setiap mendapatkan terapi dari dokter maka petugas wajib membaca ulang atau readback yang telah disampaikan oleh dokter. Jika tidak jelas maka petugas harus mengeja A-B-C-D nya. Dokter ketika visite maka petugas harus meminta tanda tangan pada notasi di lembar integrasi sebagai bukti bahwa yang dikonsulkan sudah benar. Komunikasi yang efektif juga berupa menjelaskan fungsi terapi tambahan dari perawat kepada pasien sedangkan komunikasi antar perawat menggunakan kacabak yaitu catat, lapor dan tulis.

\section{c. Pengetahuan Perawat tentang Penerapan SKP berupa Peningkatan Keamanan Obat yang Perlu Diwaspadai}

Obat-obatan yang memiliki ucapan maupun bentuk yang mirip harus lebih diwaspadai oleh petugas agar tidak terjadi kesalahan saat pengambilan obat. Obat yang pekat juga tidak boleh disimpan didalam ruangan. Kesalahan yang terjadi di rumah sakit sebagian besar disebabkan oleh kesalahan dalam pemberian obat. Berikut ini beberapa kutipan pernyataan informan tentang pengetahuan mereka akan penerapan SKP berupa peningkatan obat yang perlu diwaspadai:

"Kewaspaan obat itu mungkin untuk LASA. Obat-obat yang hampir mirip mulai dari nama atau mungkin dari bentuknya. Dari penyebutannya itu perlu kita double dek, jadi kita cek bener gak namanya ini”. (I0101050717.06) 
"Kayak obatnya high alert itu diberikan ada tandanya. Terus ada obat dengan nama yang sama untuk penempatannya gak boleh berdekatan”. (O0104130917.07)

Keamanan obat yang perlu diwaspadai menurut beberapa informan adalah Obat LASA yaitu Look Alike Sound Alike yang berarti obat-obatan yang memiliki bentuk dan pengucapan yang hampir sama. Lasa mempunyai penataan tersendiri yaitu peletakannya tidak boleh bersebelahan atau sebaris, diberi obat yang berbeda jenisnya yang diletakkan diantara dua obat yang mirip. Obat high alert merupakan obat yang pekat dan tidak boleh disimpan di dalam ruangan. Obat Lasa diberi stiker warna kuning sedangkan untuk yang high alert diberi stiker warna merah. Obat-obatan emergency disimpan didalam emergency kit dan jika ada yang digunakan maka dalam waktu tiga jam harus sudah diganti dengan yang baru. Selain itu kewaspadaan obat itu berupa pengecekan obat oleh petugas apakah sudah sesuai dengan saran dari dokter. Petugas juga harus mengecek ulang obat yang diberikan kepada pasien dan mengecek juga dari apotik.

\section{d. Pengetahuan Perawat tentang Penerapan SKP berupa Kepastian Tepat Lokasi, Tepat Prosedur dan Tepat Pasien Operasi}

Pengetahuan perawat berupa tepat lokasi, tepat prosedur dan tepat pasien operasi berfungsi agar tidak terjadinya kekeliruan pada pasien yang menjalani pembedahan. Berikut ini beberapa kutipan pernyataan informan:

'Tepat penandaan luka operasi itu, tepat pasien, tepat prosedur, tepat penandaan luka operasi. Ya sesuai dengan ini apa prosedur penandaannya kalo disini penandaan luka operasi ditandai dengan tanda panah yang dilakukan oleh DPJP'.' (O104130917.09)

"Misalkan yang fraktur kanan mau dioperasi berarti harus ditandai dengan bagian kanan. Penandaan itu oleh dokter penanggung jawab dengan tanda silang dan itu kalo tepat operasi. Kalo ketepatan pasien operasi, seumpamanya kita identifikasi ke pasiennya. Untuk prosedurnya biasanya setelah KIE mengisi lembar persetujuan antara pasien dan petugas. Kemudian menjelaskan tujuannya, apa yang akan terjadi, risiko-risikonya" (KH106140917.04)

Beberapa informan menyatakan bahwa sebelum dilakukan tindakan operasi, dokter mengidentifikasi pasien terlebih dahulu, harus ada penandaan daerah yang akan dioperasi menggunakan spidol lalu memberi tanda panah khususnya untuk daerah yang ganda. Penandaan itu dilakukan ketika pasien dalam keadaan sadar. Informan menyatakan bahwa tepat pasien operasi adalah dengan mencocokkan nama pasien dan gelang yang terpasang di tangan pasien. Dia juga menyatakan bahwa tepat prosedur itu berarti tindakan yang dilakukan harus sesuai dengan saran dokter. Menurut informan keenam bahwa pemberian tanda pada 
pasien yang akan dioperasi berupa tanda silang, sedangkan menurut informan ketujuh penandaannya diberi tanda centang.

\section{e. Pengetahuan Perawat tentang Penerapan SKP Berupa Pengurangan Risiko Infeksi}

Perawat harus mengetahui pengurangan risiko infeksi pada pasien agar pasien saat menjalani pengobatan di rumah sakit kondisinya tidak semakin memburuk terkena infeksi dari rumah sakit. Berikut ini beberapa kutipan pernyataan informan tentang pengetahuan mereka akan penerapan SKP berupa pengurangan risiko infeksi:

"Ya mulai cuci tangan, jadi sebelum ke pasien cuci tangan dulu, terus kemudian setelah dari pasien kita juga cuci tangan setelah itu APD dilengkapi. jadi semua tindakan kita selalu pake handskun”. (I0101050717.04)

"Kita sebelum tindakan atau setelah ke pasien kita harus cuci tangan. Cuci tangan bisa pake handsrub ataupun handwash. Biasanya kita pake handsrub, kalo misalkan tangan kita gak kotor. Kalo misalkan habis dari pasien tangan kita kotor kita pake cuci tangan pake sabun”. (KH106140917.06)

Informan menyatakan bahwa untuk mengurangi risiko pasien terkena infeksi selama berada di rumah sakit adalah petugas harus mencuci tangan baik sebelum maupun sesudah dari pasien. Mencuci tangan bisa menggunakan handrub jika tangan petugas tidak kotor sedangkan penggunaan handwash ketika tangan petugas sangat kotor sekali. Setiap akan ke pasien petugas juga menggunakan sarung tangan atau handskun. Selain itu, untuk pasien yang menular diisolasi atau diletakkan tersendiri ruangannya. Pemilihan sampah juga sangat penting yaitu memisahkan antara sampah medis dan sampah non medis. Sampah yang infeksius harus tertutup rapat. Penggunaan jarum suntik juga harus sekali pakai untuk mengurangi terjadinya infeksi pada pasien.

\section{f. Pengetahuan Perawat tentang Penerapan SKP Berupa Pengurangan Risiko Pasien Jatuh}

Adanya pasien jatuh selama dirumah sakit dapat dihindari jika para petugas mengetahui bagaimana pencegahan dan mengurangi risiko jatuh pada pasien. Seringkali pasien jatuh disebabkan oleh kelalaian dari petugas. Berikut ini beberapa kutipan pernyataan informan tentang pengetahuan mereka akan penerapan SKP berupa pencegahan risiko pasien jatuh:

"Dipasang klip kuning. kalo pasien pas operasi baru masuk itu selalu kita naikkan bednya. Itu kan bednya kanan kiri”. (P103060717.08)

"Selain memasang ini tanda risiko jatuh, terus memasang pagar. Kita komunikasi dengan keluarga pasien untuk membantu menjaga pasien dalam ini aktivitasnya gitu”. (O104130917.10) 
Informan menyatakan bahwa untuk mengurangi risiko jatuh pada pasien maka ada pengkajian pasien yang dimasukkan ke dalam kategori risiko jatuh yang ringan, sedang atau berat. Petugas mengisi lembar risiko jatuh tersendiri baik itu pasien anak-anak maupun dewasa. Petugas menjelaskan kepada pasien tentang risiko jatuh seperti apa dan penanganannya. Selain itu pasien risiko jatuh juga harus dipasang gelang berwarna kuning, menaikkan pagar tempat tidur, tanda risiko jatuh yang dipasang pada tiang infus. Pasien juga dijaga oleh minimal satu orang dari keluarga, jika ke kamar mandi lampu harus dinyalakan serta harus ada yang menemani.

\section{Diskusi}

Perawat yang memiliki pengetahuan tentang keselamatan pasien berguna untuk mencegah mereka melakukan berbagai kesalahan kepada pasien sehingga tidak menyebabkan pasien bertambah sakit selama dirawat inap di rumah sakit. Jika perawat memiliki pengetahuan yang baik terhadap penerapan patient safety ini maka otomatis perilaku untuk menjamin keselamatan pasien ini akan terus berjalan (6).

\section{Pengetahuan Perawat tentang Penerapan SKP berupa Ketepatan Identifikasi Pasien.}

Pengetahuan perawat di Ruang Rawat Inap RS X telah baik, hal ini terlihat dari cara mereka menerapkan identifikasi dengan minimal dua identitas pasien yaitu nama lengkap dan tanggal lahir pasien. Selain itu perawat juga mengidentifikasi pasien menggunakan gelang identitas yang terpasang ditangan pasien. Keselamatan pelayanan di rumah sakit salah satunya dimulai dari ketepatan identifikasi pasien. Penelitian ini sesuai dengan penelitian yang dilakukan oleh Setiyani,et al.(2016) yang menyatakan bahwa perawat di Ruang Rawat Inap Kemuning RSU Kabupaten Tangerang sebagian besar sudah mengimplementasikan identifikasi dengan minimal dua identitas pasien (nama lengkap dan tanggal lahir pasien atau nomor rekam medis) (7).

Berdasarkan Permenkes RI Nomor 1691 (2011), dalam melakukan identifikasi pasien tidak boleh memakai nomor kamar tempat pasien berada tetapi memakai dua identitas pasien yaitu boleh nama, tanggal lahir maupun nomor rekam medis (7). Identifikasi pasien harus dilaksanakan dengan tepat dan benar oleh tenaga medis yang bertanggungjawab (8). Risiko keselamatan terjadi ketika terdapat ketidakcocokan antara pasien dengan item pelayanan yang seharusnya diterima baik yang bersifat diagnostik, terapeutik maupun pelayanan pendukung lainnya (9). Menurut WHO, salah identifikasi pasien diidentifikasi sebagai akar penyebab banyak kesalahan yang terjadi (7).

\section{Pengetahuan Perawat tentang Penerapan SKP berupa Peningkatan Komunikasi} yang efektif 
Pengetahuan perawat tentang peningkatan komunikasi yang efektif sudah baik hal ini terlihat dari kepahaman mereka saat melaporkan keadaan pasien kepada dokter. Perawat menggunakan metode S-Bar dalam berkomunikasi dan mereka juga paham bahwa harus membaca ulang apa yang disarankan oleh dokter. Perawat yang tidak jelas saat menerima terapi yang diberikan oleh dokter maka mereka mengeja A-B-C-D nya. Hasil penelitian ini sama dengan penelitian Nasution et al., (2013) didapatkan bahwa perawat yang berada di ruang rawat inap ketika berkomunikasi mapun melaporkan kondisi pasien via telphone, mereka menggunakan metode SBAR yaitu Situation, Background, Assessment, dan Rekommendation (SBAR) (10).

Upaya untuk menurunkan insiden keselamatan pasien yang dapat dilakukan salah satunya dengan cara Patient Safety yaitu komunikasi efektif SBAR (11). SBAR adalah suatu metode untuk mengkomunikasikan informasi yang penting agar dapat menjamin dan melindungi keselamatan pasien (12). Adanya komunikasi yang baik dapat mencegah atau meminimalkan munculnya kejadian yang tidak diharapkan. Komunikasi yang baik akan merubah kesadaran individu-individu sehingga dapat merubah pelayanan yang diberikan pada saat di lapangan (13). Maka dari itu diperlukan suatu komunikasi yang efektif diantara beberapa pihak antara pasien, dokter, perawat maupun tenaga kesehatan yang lain agar tidak terjadi suatu kesalahan (12).

\section{Pengetahuan Perawat tentang Penerapan SKP berupa Peningkatan Keamanan Obat yang Perlu Diwaspadai}

Pengetahuan perawat tentang peningkatan keamanan obat yang perlu diwaspadai sudah baik, hal ini terlihat dari pemahaman mereka cara meletakkan obat-obatan LASA diletakkan terpisah dan tidak bersebelahan. Obat-obatan high alert tidak boleh disimpan didalam ruangan. Hal ini serupa dengan penelitian yang dilakukan oleh Isasih dan Mudayana diperoleh bahwa menyimpan obat-obatan yang perlu diwaspadai dengan meletakkannya pada tempat terpisah serta tidak menyimpan pada unit perawatan pasien dilakukan untuk meningkatkan keamanan obat yang perlu diwaspadai (14) .

Suatu kesalahan serius (sentinel event) serta berakibat sesuatu yang tidak dikehendaki (adverse outcome) yang disebabkan oleh obat-obatan disebut high-alert medication atau obat yang perlu diwaspadai sehingga dalam perencanan pengobatan pasien di setiap kegiatan harus memperhatikan patient safety. NORUM (Nama Obat Rupa dan Ucapan Mirip) atau LASA (Look Alike Sound Alike) merupakan obat yang perlu diwaspadai karena kemiripan nama maupun bentuk (15). 


\section{Pengetahuan Perawat tentang Penerapan SKP berupa Kepastian Tepat Lokasi, Tepat Prosedur, Tepat Pasien Operasi}

Tidak semua perawat memiliki pengetahuan yang baik tentang kepastian tepat lokasi, tepat prosedur maupun tepat pasien operasi karena ada salah satu diantara informan menyatakan bahwa pemberian tanda pasien yang akan dioperasi dengan tanda silang. Sebagian besar pengetahuan perawat sudah baik karena mereka melakukan pengecekan identitas pasien, memberikan tanda panah pada daerah yang akan dioperasi serta tepat prosedur semua tindakan sesuai dengan perintah dokter. Salah satu sasaran dalam safety surgery ada tentang tim bedah yang melakukan operasi pada pasien serta lokasi tubuh yang benar. Hal ini dilakukan untuk meningkatkan keselamatan pasien selama prosedur pembedahan, menghindari terjadinya kesalahan lokasi operasi ataupun kesalahan prosedur operasi (16). Perawat yang memiliki pengetahuan yang tinggi tentang penerapan patient safety diharapkan mempunyai pemahaman yang tinggi juga terkait pentingnya penerapan patient safety selama memberikan pelayanan keperawatan kepada pasien (6).

\section{Pengetahuan Perawat tentang Penerapan SKP berupa Pengurangan Risiko Infeksi}

Pengetahuan perawat terhadap pengurangan risiko infeksi sudah baik karena mereka tahu cara mencegah infeksi dengan mencuci tangan, menggunakan alat pelindung diri, pemilihan sampah sesuai dengan sampah medis ataupun non medis. Menurut penelitian Yulianti (2011) dalam Wulandari dan Sholikah (2017) didapatkan hasil bahwa ada hubungan antara pelaksanaan universal precaution dengan pengetahuan perawat (17). Salah satu penerapan universal precaution pada perawat adalah dengan melakukan cuci tangan. Pengetahuan merupakan elemen yang sangat penting untuk terbentuknya tindakan seseorang (17).

Infeksi Nosokomial (INOS) adalah salah satu infeksi yang menyebabkan tingginya angka kesakitan maupun kematian didunia yaitu sekitar 5000 kematian dan menyebabkan pasien harus dirawat 2,5 kali lebih lama dari yang seharusnya (18). Mencuci tangan ketika melakukan berbagai tindakan kepada pasien di rumah sakit merupakan cara paling ampuh untuk mencegah terjadinya infeksi nosokomial. Terjadinya infeksi nosokomial dapat diturunkan sebesar 20-40\% dengan melakukan cuci tangan (7). Mencuci tangan, memakai alat pelindung diri contohnya masker dan sarung tangan merupakan salah satu tindakan pencegahan risiko tertular maupun menularkan infeksi (19). Alat pelindung diri (APD) sangat penting untuk dipakai oleh seorang perawat dalam melaksanakan tugas. Alat pelindung diri (APD) ini digunakan atau dipakai oleh petugas memiliki dua fungsi, yaitu untuk kepentingan penderita dan sekaligus untuk kepentingan petugas itu sendiri (19). 


\section{Pengetahuan Perawat tentang Penerapan SKP berupa Pengurangan Risiko Pasien Jatuh}

Informan memiliki pengetahuan yang baik tentang penerapan pengurangan risiko jatuh pada pasien. Mereka melakukan pemasangan gelang kuning, melakukan pengkajian pasien risiko jatuh, menaikkan pagar tempat tidur, memberikan tanda risiko jatuh, menjelaskan pada pasien ataupun keluarga bahwa pasien berisiko jatuh. Serupa dengan hasil penelitian yang dilakukan oleh Nugraheni, et al. (2017) didapatkan terdapat hubungan antara pengetahuan perawat tentang patient safety dengan mencegah pasien yang berisiko untuk jatuh (20).

Jatuh dapat dicegah dengan melakukan identifikasi terhadap keberadaan faktor-faktor risiko jatuh baik internal maupun eksternal. Proses identifikasi dapat dilakukan menggunakan instrument pengkajian (screening tools) yang sudah baku antara lain Modified Falls-Efficacy Scale (MFES), The Morse Falls Scale Assessment (21). Resiko pasien untuk terjatuh sangat tinggi, oleh karena itu perlu berbagai cara agar dapat mencegah hal tersebut terjadi. Salah satu contoh untuk mencegah risiko pasien jatuh adalah dengan memasang pengaman tempat tidur terutama pada pasien dengan kesadaran yang menurun serta gangguan motilitas (22).

\section{Kesimpulan}

Sebagian besar perawat rawat inap RS X mempunyai pengetahuan yang baik tentang penerapan sasaran keselamatan pasien. Mereka mengetahui bagaimana penerapan enam sasaran keselamatan pasien tersebut. Hanya sebagian kecil yang tidak mengetahui penerapan pemberian tanda pada pasien yang akan dioperasi. Penting sekali adanya pengetahuan perawat tentang patient safety ini agar tidak terjadi kesalahan pada pasien pada saat melakukan tindakan.

\section{Daftar Pustaka}

1. Muliana A dan Mappanganro A. Hubungan Pengetahuan dan Sikap Perawat dalam Penerapan Patient Safety Goal: Identifikasi Pasien di Rumah Sakit Ibnu Sina Yw-Umi Makassar. Jurnal Ilmiah Kesehatan Diagnosis. 2016; 9(1): 117-125.

2. Cahyono A. Hubungan Karakteristik dan Tingkat Pengetahuan Perawat terhadap Pengelolaan Keselamatan Pasien di Rumah Sakit. Jurnal Ilmiah WIDYA. 2015; 3(2): $97-$ 102.

3. Brasaite I. Health Care Professionals'Knowledge and Attitudes Regarding Patient Safety and Skills for Safe Patient Care, University of Tampere. 2016.

4. Herawati Y. Budaya Keselamatan Pasien di Ruang Rawat Inap Rumah Sakit X Kabupaten Jember. IKESMA. 2015; 11(1): 52-60. 
5. Bawelle S, Sinolungan J dan Hamel R. Hubungan Pengetahuan dan Sikap Perawat dengan Pelaksanaaan Keselamatan Pasien (Patient Safety) di Ruang Rawat Inap RSUD Liun Kendage Tahuna. ejournal keperawatan (e-Kp). 2013; 1(1): 1-7.

6. Darliana D. Hubungan Pengetahuan Perawat dengan Upaya Penerapan Patient Safety di Ruang Rawat Inap Rumah Sakit Umum Daerah Dr. Zainoel Abidin Banda Aceh. Idea Nursing Journal. 2016; VII(1): 61-69.

7. Setiyani MD, Zuhrotunida dan Syahridal. Implementasi Sasaran Keselamatan Pasien di Ruang Rawat Inap RSU Kabupaten Tangerang. JKFT. 2016; Edisi No.2: 59-69.

8. Sakinah S, Wigati PA dan Arso SP. Analisis Sasaran Keselamatan Pasien Dilihat dari Aspek Pelaksanaan Identifikasi Pasien dan Keamanan Obat di RS Kepresidenan RSPAD Gatot Soebroto Jakarta. Jurnal kesehatan Masyarakat (e-Journal). 2017; 5(4): 145-152.

9. Anggraeni D, Hakim L dan Widjiati C. Evaluasi Pelaksanaan Sistem Identifikasi Pasien di Instalasi Rawat Inap Rumah Sakit. Jurnal Kedokteran Brawijaya. 2014; 28(Suplemen No.1): 99-104.

10.Arruum D, Salbiah dan Manik M. Pengetahuan Tenaga Kesehatan dalam Sasaran Keselamatan Pasien di Rumah Sakit Sumatera Utara. Idea Nursing Journal. 2015; 6(22): $1-6$.

11.Rezkiki F dan Utami GS. Faktor yang Berhubungan dengan Penerapan Komunikasi SBAR di Ruang Rawat Inap. Jurnal Human Care. 2017; 1(2).

12.Rokhmah NA dan Anggorowati. Komunikasi Efektif dalam Praktek Kolaborasi Interprofesi sebagai Upaya Meningkatkan Kualitas Pelayanan. Journal of Health Studies. 2017; 1(1): 65-71.

13. Mudayana AA. Pelaksanaan Patient Safety oleh Perawat di RS PKU Muhammadiyah Yogyakarta. Jurnal Kesehatan "Samodra Ilmu”. 2015; 6(2): 145-149.

14.Isasih WD dan Mudayana AA. Naskah Publikasi Analisis Implementasi Sasaran keselamatan Pasien di RSUD Kabupaten Lombok Utara. Prosiding-SEMNAS \& Call for Papers. ISBN:978-602-361-069-3.

15.Yuwantina L. H. Peningkatan Program Patient Safety Melalui Metode Failure Mode and Effect Analysis. Jurnal Administrasi Kebijakan kesehatan. 2012; 10(2): 61-67.

16.Klase S, Pinzon RT dan Meliala A. Penerapan Surgical Safety Checklist WHO di RSUD Jaraga Sasameh Kabupaten Barito Selatan. Berkala Ilmiah Kedokteran Duta Wacana. 2016; 1(3): 173-182.

17.Wulandari R dan Sholikah S. Pengetahuan dan Penerapan Five Moments Cuci Tangan Perawat di RSUD Sukoharjo. Gaster. 2017; 15(1): 18-27. 
18.Susilo DB. Kepatuhan Pelaksanaan Kegiatan Hand Hygiene pada Tenaga kesehatan di Rumah Sakit X Surabaya. Jurnal Wiyata. 2015; 2(2): 200-204.

19.Bachrun E. Hubungan Tingkat Pengetahuan Perawat tentang Patient Safety terhadap Penerapan Sasaran V (Pengurangan Resiko Infeksi Terkait Pelayanan Kesehatan). Jurnal Kesehatan Masyarakat STIKES Cendekia Utama Kudus. 2017; 5(1): 36-42.

20.Nugraheni M, Widjasena B, Kurniawan B dan Ekawati. Faktor-Faktor yang Berhubungan dengan Pencegahan Jatuh pada Pasien Risiko Jatuh oleh Perawat di Ruang Nusa Indah RSUD Tugurejo Semarang. Jurnal Kesehatan Masyarakat (e-Journal). 2017; 5(2): 121130.

21.Asih W dan Tambunan. Pengaruh Program Pencegahan Jatuh Berupa Edukasi dan Latihan Kekuatan Otot terhadap Faktor Risiko Jatuh yang Dimiliki oleh Lansia di Balai Perlindungan Sosial Tresna Werdha (BPSTW) Ciparay Bandung. Immanuel Jurnal Ilmu Kesehatan. 2015; 9(2): 537-552.

22.Kilateng EW, Ake J dan Makausi E. Hubungan Pengetahuan Perawat tentang Patient Safety dengan Tindakan Pencegahan Risiko Pasien Jatuh di Ruang Interna RSUD Maria Walanda Maramis Airmadid. E-Jurnal Sariputra. 2015; 2(2): 96-1-03. 